\title{
The creation of energy efficient hybrid vehicles in the Russian Federation
}

The paper shows the development of the NAMI Russian State Scientific Research Center associated with advanced research in the field of hybrid vehicles. The stages of design, creation and testing of hybrid vehicles with range extender system. The paper presents the results of bench and road tests of hybrid vehicles with range extender system. The peculiarities of creation and operation of hybrid vehicles for countries with difficult climatic conditions, for example, the Russian Federation.

Key words: hybrid vehicle, range extender, traction battery, energy efficiency, climatic conditions

\section{Introduction}

Individual mobility is a basic need of humans. Growing income goes hand in hand with more individual mobility. In early 2000, we had a total about 750 million vehicle, but in 2016, we have over 1 billion vehicle in the world. Currently most of the world's automotive countries link the solution of a complex ecological safety and problems of energy saving by regulating $\mathrm{CO}_{2}$ emissions, as well as increasing adoption in the production of hybrid vehicles, which can significantly reduce the pollution on the planet. [1,2].

According to the European Commission for Transport's forecasts, by 20207 per cent of passenger and light commercial transport in Europe is going to have electric drives, by 2030 this figure is going to increase to 31 per cent. The tendency to increase amount of hybrid vehicles and electric vehicles defines extension of geography of their use, inclusive of northern regions with low temperatures and long winters.

\section{Main part}

Electric transport is an integral part of our lives, but it has several significant shortcomings such as limited mileage on a single charge, the lack of well-developed infrastructure of charging stations, the complexity when operating in conditions of negative temperatures, etc., these disadvantages slow down its promotion in the global markets, especially in countries with difficult climate and long distances between cities. The Russian Federation is a country with a cold climate prevalent in most areas: average annual temperatures in the Northern and Central regions are in the range $0 \ldots-22^{\circ} \mathrm{C}$ that you can see on the temperature map presented in Figure 1.

While electric vehicle shall be operated over the full temperature range of the region in which it is used, the critical factor is the lowest temperature. The average winter temperature in Russia is Krasnodar $-2^{\circ} \mathrm{C}$, Moscow $-6^{\circ} \mathrm{C}$, Irkutsk $-23^{\circ} \mathrm{C}$. While in Moscow, winter temperatures can be below $-30^{\circ} \mathrm{C}$, and in Irkutsk - below $-50^{\circ} \mathrm{C}$ (Fig. 2). Lithium-ion battery system can operate in a rather wide range of temperatures, but there are extrema, which is worth remembering all the time, especially in countries with cold climate and a lot of time zones, such as Russia.

In the Northern regions of Russia, the annual duration of the period of negative temperatures can reach 250-270 days. Electric and hybrid vehicles doesn't have the capability of temperature control of the traction batteries for their normal functioning in such conditions of temperature that negatively affects the durability of the traction batteries.

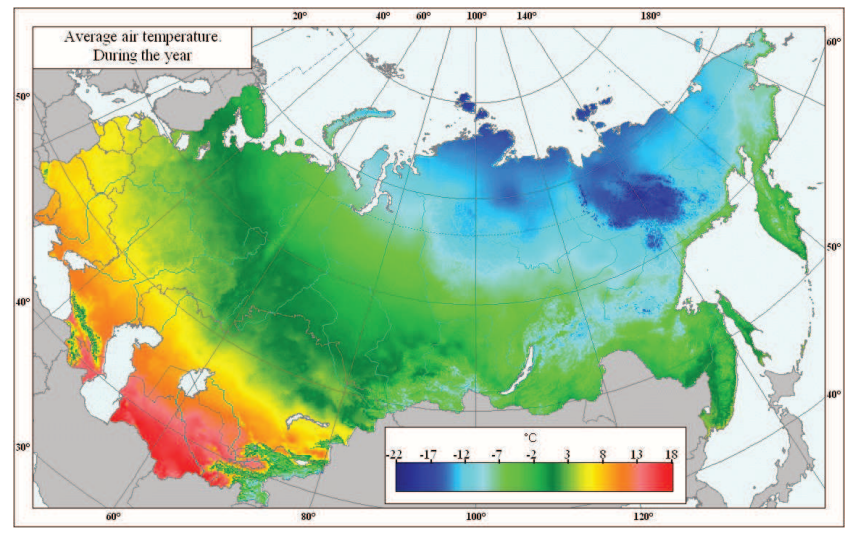

Fig. 1. Average air temperature during the year in Russia

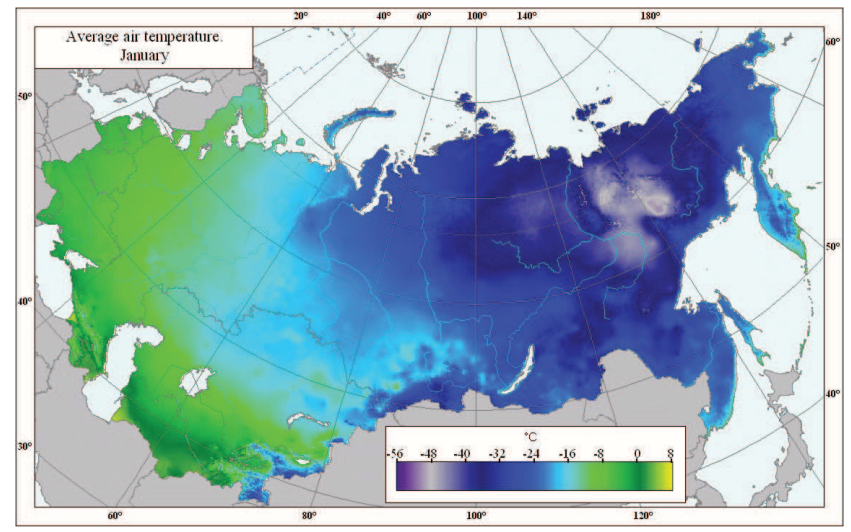

Fig. 2. Average minimum air temperature during the year in Russia

For example, in the instruction manual of the electric vehicle Tesla Model S indicate that to save battery you must fulfill the following conditions: the traction battery of an electric vehicle should be kept solely at zero temperature; avoid idle running car (30 minutes) in the cold; do not operate the electric vehicle at temperatures below $-15^{\circ} \mathrm{C}$; to warm up the electric vehicle after a long idle in the cold when you connect to the network and not from the battery. This determines the relevance of studying the properties of battery systems included in vehicles on electricity, at low temperatures. 
Modern battery systems of hybrid and electric vehicles are designed, as a rule, on the basis of lithium - ion batteries of various types of electrochemical systems. Negative consumer characteristics of all lithium batteries is that they are very poorly adapted to sub-zero temperatures. They usually allow you to discharge at temperatures below $-10 \ldots-20^{\circ} \mathrm{C}$ (reduction of the capacity and output of current), a charge - only at positive temperature.

At temperatures below $+5^{\circ} \mathrm{C}$, the charge current must be lowered. The charge is not valid when the temperature is below $0^{\circ} \mathrm{C}$, in this case the external changes are not observed, but the chemical processes necessary for the correct operation of the battery will be broken, which can lead to permanent damage to the battery. During charging, at this temperature, the particles of lithium metal can be deposited on the anode. This coating of deposited lithium will not be lost when cycles of charge/discharge. Batteries with such a coating become less fault tolerant and can fail under vibration. [3-6].

In the world, developed and patented a large number of technical decisions concerning control systems and stabilization of the thermal state of the traction battery, having in its composition the elements of heating and cooling. In such devices are mainly used liquid temperature control system. Their disadvantages lie in the structural complexity. In addition, an emergency exists the possibility that the working fluid in the cavity of the battery container.

Frequently used air system the destination. Their design is virtually indistinguishable from liquid systems. The air system can be considered more promising, as the large heat capacity of the coolant compared to air in this case loses its relevance, given the relatively small magnitude of energy flow per unit volume, with temperature control of the battery.

Recently widely, especially in China, is under development that uses as the working parts of the thermostat thermoelectric probes such as Peltier elements. Such devices simplify the design of the battery have a higher energy performance.

As already mentioned, one of the key drawbacks that prevent widespread use of electric vehicles is the limited range of their actions. The existing problem is difficult to solve by increasing the capacity of the battery, as it leads to increase the cost of the vehicle (the vehicle) and weight gain, which in turn increases the energy consumption for overcoming the motion resistance forces. Besides the big battery has a long charge time (up to 7-8 hours). These shortcomings imposed on the climatic features of our country, exacerbate the problems hampering the popularization of electric vehicles.

The world's leading vehicle manufacturers and research organizations of the automotive industry, knowing about these problems, focus on the establishment of various systems of hybrid and electric vehicles, improvement of control algorithms.

Specialists of NAMI Russian State Scientific Research Center was developed an experimental model of a hybrid vehicle with a Range Extender system and innovative system of temperature control (Fig. 3) [7, 8]. As the combined power on this vehicle used the engine-generator set for extended range electric vehicles that don't have rigid kinematic connection with the drive shaft of the vehicle, in the world known as the Range Extender.

The Range Extender installed into the experimental prototype of the motor vehicle consists of a small operating volume internal combustion engine and electrical machine operating in a generator mode. This unit is experimental and allows to refine an algorithm and work out a method of definition of the Range Extender required capacity and energy capacity of the accumulator module, which will allow to use different variants of their arrangement on chassis of various class hybrid vehicles. Range Extender comprises the engine and the $20 \mathrm{~kW} / 270 \mathrm{~V}$ generator.

Table 1. Technical characteristics of the Range Extender

\begin{tabular}{|l|c|}
\hline Fuel type & Gasoline $\geq 90$ \\
\hline Oil type & $10 \mathrm{~W} / 30 \mathrm{SAE}$ \\
\hline Nominal voltage (DC) & $270 \mathrm{~V} \mathrm{DC}$ \\
\hline Maximum capacity [kW] & $20 \mathrm{~kW}$ \\
\hline Fuel efficiency [min] & $0.51 / \mathrm{kW} \cdot \mathrm{h}$ \\
\hline Range extender dimensions [mm] & $667 \times 451 \times 698$ \\
\hline
\end{tabular}

The Range Extender has a transverse position in the vehicle's luggage compartment, on a place of the removed spare wheel well (Figures 4, 5).
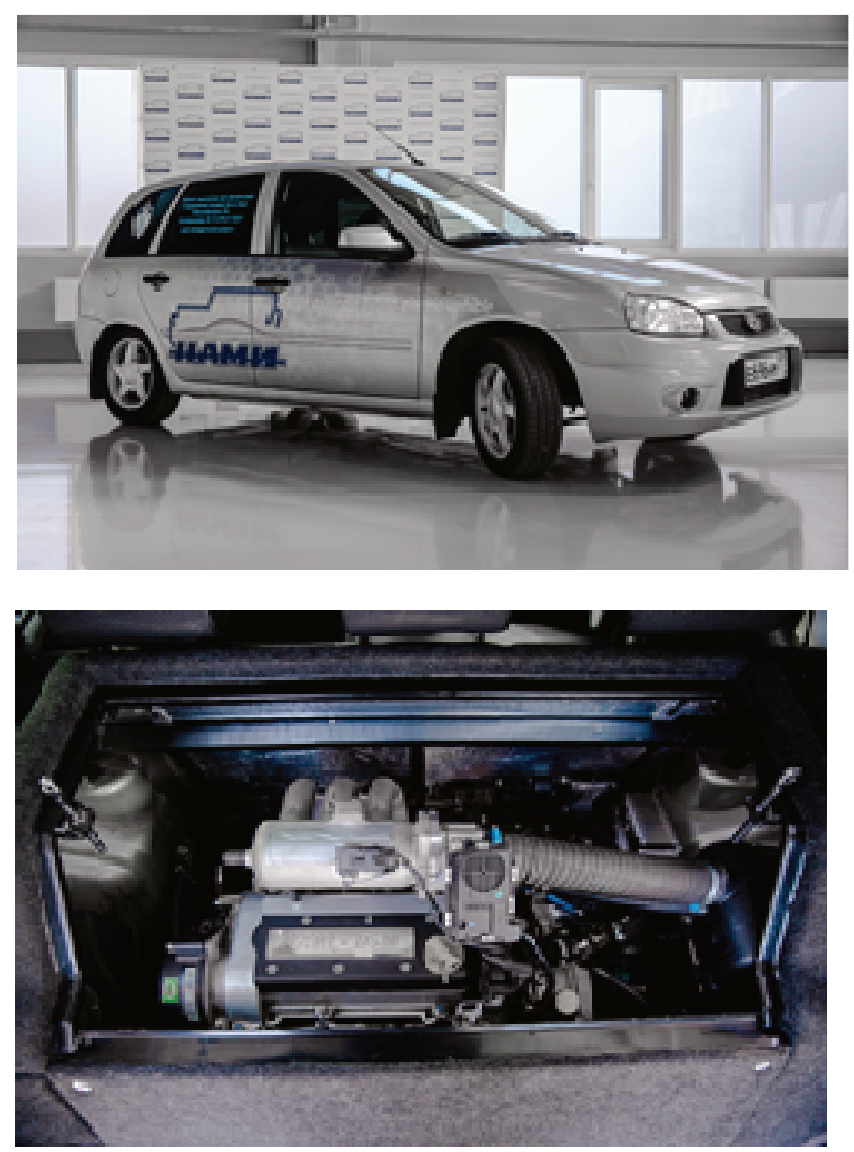

Fig. 3. Hybrid vehicle with Range Extender

The Range Extender is separated from the passenger compartment of the vehicle by special partitions equipped 
with thermal insulating and noise absorbing materials. Control over the combined energy unit is performed via the information controlling interaction of the vehicle's electric traction drive, consisting of the electric machine, the invertor and the accumulator battery, and the Range Extender. The system's software includes the control over combined energy unit algorithm that was developed in MATLAB/Simulink and AVL Cruise, preliminary tested on a mathematical model of the vehicle with the combined energy unit (software-in-the-loop), as well as utility driver programs that perform data exchange and interaction of hardware and software parts of the control system.

Components composition and information connections of the combined energy unit control system are shown on the Figure 4. The arrows indicate directions of the information connections, above the arrows there are names of the used information protocols (RS-232, CAN). The combined energy unit control algorithm is in the controller that interacts with components of the electric traction drive control system - the electric machine's invertor and the Battery Management System (BMS), as well as with the Range Extender control unit. The control algorithm developed in the MATLAB/Simulink and AVL Cruise environment is translated into the C-language code, compiled and "flashed" into the combined energy unit controller. The control system included into the controller uses for its operation feedback signals that come from the combined energy unit's components via their control units.

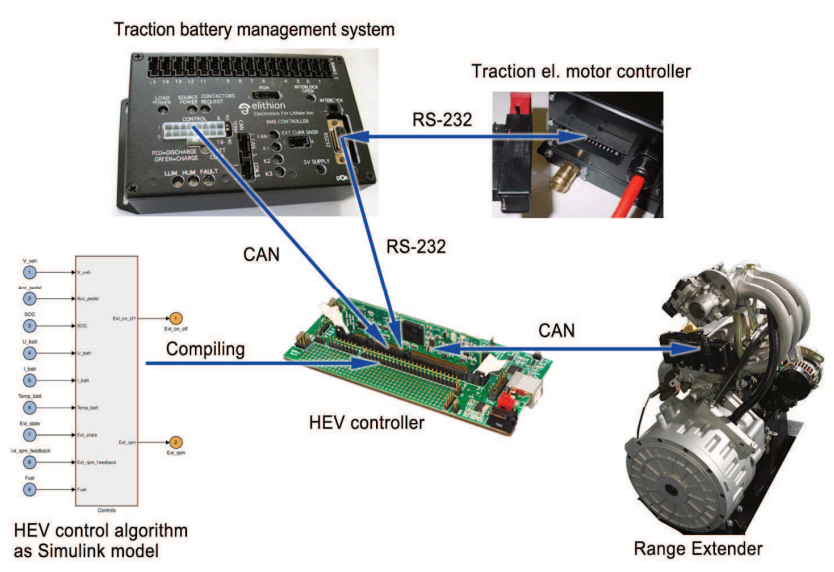

Fig. 4. Control system structure

For hybrid vehicle with Range Extender has been developed a system of accumulation and storage of electrical energy with innovative thermostatting's systems (Fig. 5).

The system temperature control consists of 26 of the battery cells placed in an airtight container. The container has an inner insulating coating and built-in temperature control device, built on two thermoelectric Converter Peltier and two SPAL fans. The system thermostat is powered by the onboard battery voltage of $12 \mathrm{~V}$. In case of temperature increase in the battery pack above $+20^{\circ} \mathrm{C}$, at block enable control signal enable voltage. The signal $\mathrm{U} \pm$ is absent. Turn on the fan and the Peltier element operates in a cooling mode. The inclusion continues until the temperature drops below $+20^{\circ} \mathrm{C}$. If in conditions of low external temperatures the temperature of the battery decreases below $+10^{\circ} \mathrm{C}$, the control unit battery are formed signals enable voltage; $\mathrm{U} \pm$ and the Peltier element is switched on in heating mode. The advantage of Peltier element is small in size, the absence of any moving parts, as well as gases and liquids. Turning the direction of the current, perhaps as a cooling and heating - this allows for temperature control when ambient temperature is both above and below the temperature of the thermostat. Was carried out aerodynamic and thermal calculations temperature control system. It is possible to find the optimal layout of the battery module. The task of aerodynamic calculation was solved with the use of a complex of programs allowing to carry out solid modelling, and the integration of the movement of the air flow by the finite element method. Figure 6 shows how the airflow near the fans are distributed without significant turbulence, which minimizes the effect of surge.

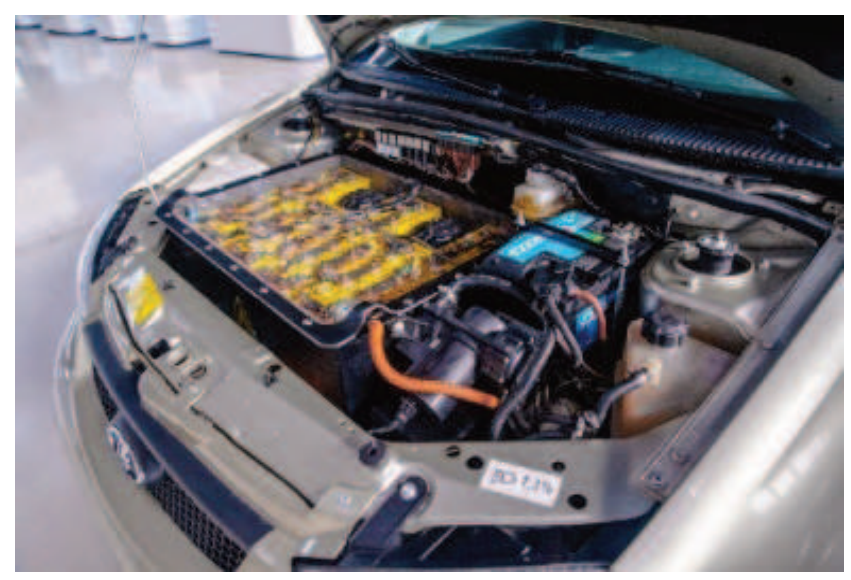

Fig. 5. General view of the engine compartment with the developed system of accumulation and storage of electrical energy

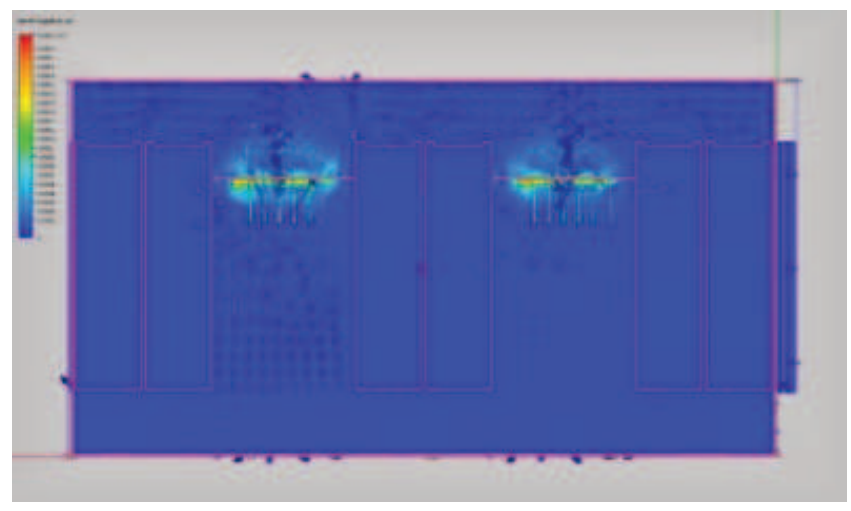

Fig. 6. Visualization of airflow near the fans

In the summer of 2016 hybrid vehicles with a Range extender system underwent comprehensive testing in the test Center "NAMI" (Fig. 7, 8).

The main results of the tests:

- maximum speed of the vehicle $134 \mathrm{~km} / \mathrm{h}$;

- regenerative braking from a speed greater than $40 \mathrm{~km} / \mathrm{h}$;

- emissions vehicle correspond to ecological class 5 (UNECE regulation No. 83);

- decrease in fuel consumption $12 . . .14 \%$ in comparison with existing analogues hybrid vehicle;

- the energy content of the traction battery $23 \mathrm{~kW} / \mathrm{h}$; 
- nominal voltage of the traction battery $305 \mathrm{~V}$;

- the thermostating system ensures a working temperature range up to $+12 \ldots+18^{\circ} \mathrm{C}$ at an external temperature of $40 \ldots+50^{\circ} \mathrm{C}$.

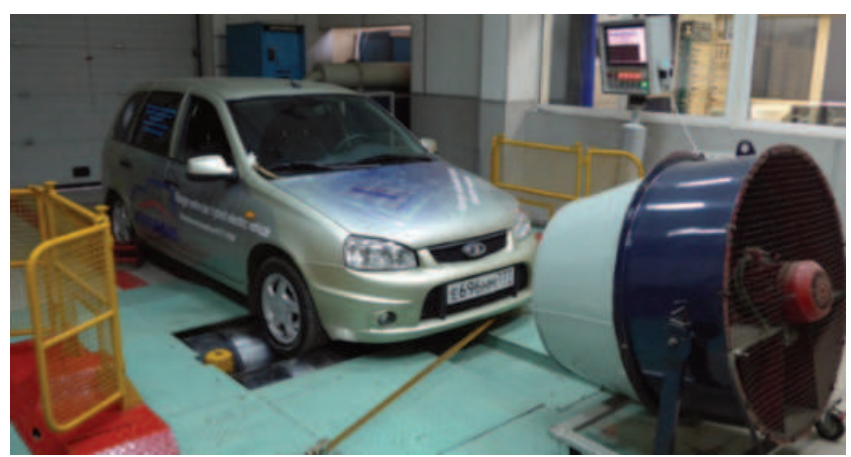

Fig. 7. Fragment of bench tests

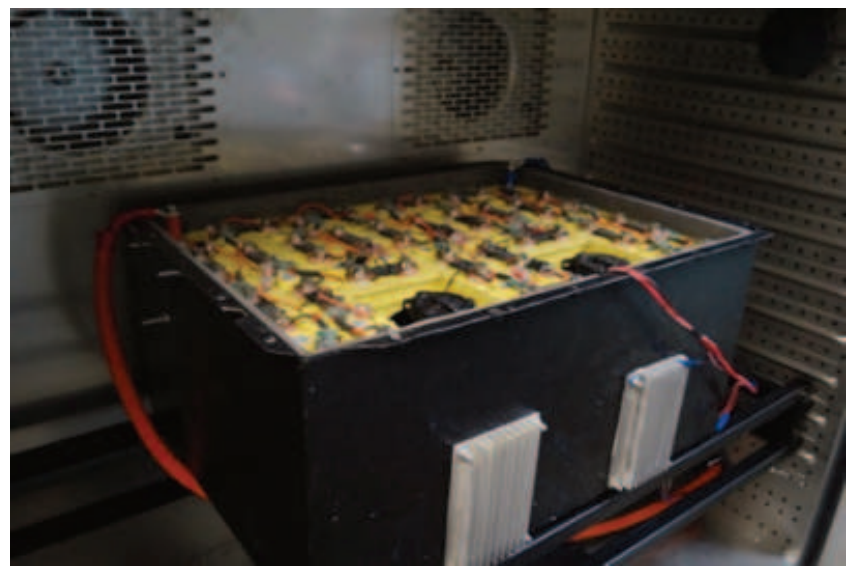

Fig. 8 Fragment tests in a heat chamber

\section{Conclusions}

1. Claimed by the manufacturers of electric performance, in particular the reserve and the required charging time, often not focused on countries with negative temperatures, and the middle Eastern climate, with excellent road and charging infrastructure and quality public services.

2. The results of the study allow to formulate the main aspects of ensuring the effective functioning of the battery systems of hybrid cars and electric vehicles in freezing conditions, so operation is not protected from the ambient temperature below $+5^{\circ} \mathrm{C}$ battery systems are not desirable, as leading to accelerated degradation of the batteries.

3. Vehicles, having in its composition a heat-insulated battery, it is allowed to leave at negative external temperatures for a limited time, decreasing with decreasing temperature.

4. When you implement independent heating of the battery, for example, by using thermoelectric converters Peltier, the daily power consumption will be at $-30^{\circ} \mathrm{C}$ of at least $1.6 \mathrm{~kW} \cdot \mathrm{h}$. Therefore, if the time long-term Parking not known, hybrid and electric vehicles must be connected to the stationary power grid or hybrid vehicles to provide periodic startup to warm the engine and recharge the battery.

5. Developed temperature control system of the electric vehicle meant to be operated in difficult climatic conditions. The practical application of the developed principle of temperature control allows to provide the function of the battery in the most favorable temperature range $20-30^{\circ} \mathrm{C}$, which in turn provides increased service life of battery is not less than $10-20 \%$. The developed system thermostat will ensure the temperature within -40 to $+50^{\circ} \mathrm{C}$

\section{Bibliography}

[1] International Energy Agency. Hybrid and electric vehicles. The electric drive delivers. 2015.

[2] MILLER, J. Propulsion systems for hybrid vehicles 2nd Edition. UK: The Institution of Engineering and Technology, 2010, 593.

[3] PESARAN, A. Battery thermal management in EVs and HEVs: issues and solutions. National Renewable Energy Laboratory. 1617 Cole Blvd. Golden, Colorado 80401. Advanced Automotive Battery Conference, Las Vegas, 2010.

[4] KARPUKHIN, K., TERENCHENKO, A., SHORIN, A., BAKHMUTOV, S., KURMAEV, R. Temperature control of the battery for hybrid or electric vehicle. Biosciences Biotechnology Research Asia. 2015, 12(2), 1297-1301.
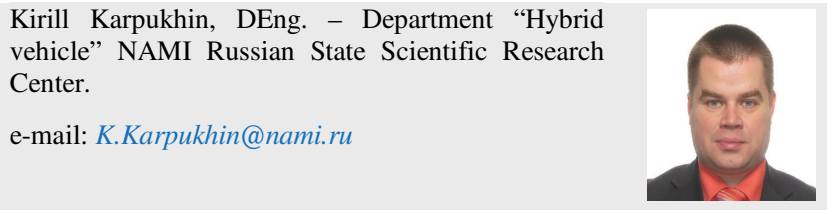

[5] KAZUKI, S., MASATOSHI, K., YOSHIYUKI, H. Hybrid vehicles, electric vehicles, fuel cell electric vehicles. Japan Automobile Research Institute, 2013, 11-13.

[6] WILEY, J. \& Sons, Ltd. Encyclopedia of automotive engineering, 201, 2696.

[7] BAKHMUTOV, S., KARPUKHIN, K., TERENCHENKO, A., KURMAEV, R., KONDRASHOV, V., SKLYARINSKII, S. Production of the electric vehicle experimental prototype with the range extender. Biosciences biotechnology research Asia. 2015, 12(Spl. Edn.), 533-538.

[8] KULIKOV, I., SHORIN, A., BAKHMUTOV, S., TERENCHENKO, A., KARPUKHIN, K. A Method of powertrain's components sizing for a range extended electric vehicle. SAE Technical Paper 2016-01-8096, 2016.

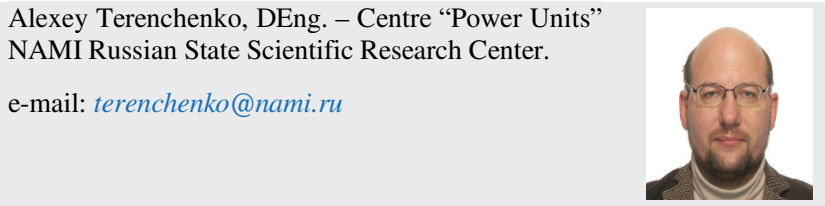

